\title{
Correction to: In Medio Stat Virtus: intermediate levels of mind wandering improve episodic memory encoding in a virtual environment
}

\author{
Philippe Blondé ${ }^{1}$ - Dominique Makowski ${ }^{1} \cdot$ Marco Sperduti $^{1} \cdot$ Pascale Piolino ${ }^{1,2}$
}

Accepted: 1 February 2022 / Published online: 18 February 2022

○) Springer-Verlag GmbH Germany, part of Springer Nature 2022

\section{Correction to: Psychological Research (2021) 85:1613-1625 https://doi.org/10.1007/s00426-020-01358-5}

In the original publication of the article, the following line in the abstract has been published incorrectly:

"We found a significant linear positive relationship between the ratio of correctly recognized items and the overall mind wandering reported after the task".

The words in bold should be replaced by the following ones:

"We found a possible linear negative relationship between the ratio of correctly recognized items and the overall mind wandering reported after the task".
The original article has been corrected.

Publisher's Note Springer Nature remains neutral with regard to jurisdictional claims in published maps and institutional affiliations.

The original article can be found online at https://doi.org/10.1007/ s00426-020-01358-5.

Philippe Blondé

philippe.blonde93@gmail.com

Dominique Makowski

dom.makowski@gmail.com

Marco Sperduti

marco.sperduti@parisdescartes.fr

Pascale Piolino

pascale.piolino@parisdescartes.fr

1 Laboratoire Mémoire, Cerveau et Cognition (URP 7536), Institut de Psychologie, Université de Paris, 71 avenue Ed. Vaillant, 92100 Boulogne Billancourt, Ile de France, France

2 Institut Universitaire de France, Paris, France 